\title{
Hydride in $\mathrm{BaTiO}_{2.5} \mathrm{H}_{0.5}$ : A Labile Ligand in Solid State Chemistry
}

Naoya Masuda, Yoji Kobayashi, Olivier Hernandez, Thierry Bataille, Serge Paofai, Hajime Suzuki, Clemens Ritter, Naoki Ichijo, Yasuto Noda, Kiyonori Takegoshi, Cédric Tassel, Takafumi Yamamoto, Hiroshi Kageyama

\section{Supporting Information}
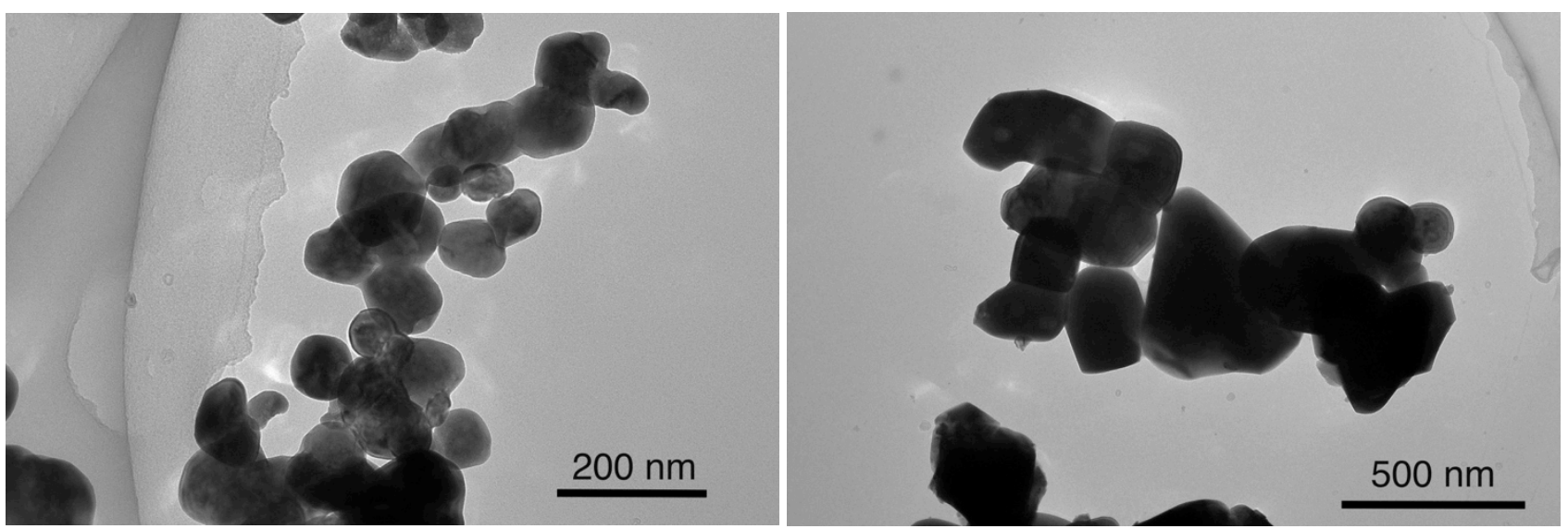

Figure S1. TEM images of precursor $\mathrm{BaTiO}_{3}$, obtained commercially. The left image shows the $100 \mathrm{~nm}$ particle size sample, while the right image shows the $300 \mathrm{~nm}$ sample.

\section{Preparation of $\mathrm{CaD}_{2}$}

About $10 \mathrm{~g}$ Ca metal is reacted with $\mathrm{D}_{2}$ gas at $600^{\circ} \mathrm{C}$. The Ca metal is mounted in a $3 / 8^{\prime \prime}$ stainless steel tube inside a $\mathrm{N}_{2}$-filled glove box, sealed on one end with stainless steel Swagelok fittings and connected one the other side to a $\mathrm{D}_{2}$ gas cylinder. A pressure gauge was connected between the $\mathrm{D}_{2}$ gas cylinder and the stainless steel tube and monitored how the total pressure inside the reactor decreased during the reaction with $\mathrm{D}_{2}$ gas. After the reaction, additional $\mathrm{D}_{2}$ gas was introduced and the whole operation was repeated until the total pressure ceased to change, usually requiring 10 cycles. Following these treatments the reactor was quenched by water and the sample was ground in a glove box. After grinding, the sample was reacted with $\mathrm{D}_{2}$ gas again as mentioned above; this process was carried out by 3 times to obtain $\mathrm{CaD}_{2}$ as a single phase.

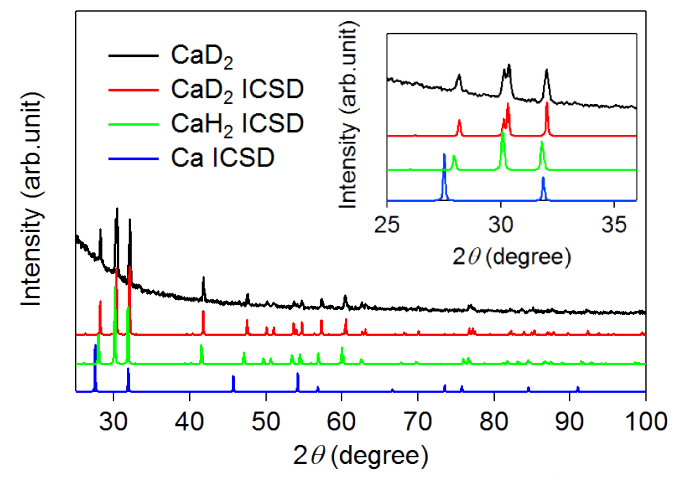

Figure S2. XRD pattern for $\mathrm{CaD}_{2}$ prepared as above. Unreacted Ca metal was not observed in the final product. The $\mathrm{CaD}_{2}$ sample was covered with Kapton tape during the XRD measurement, resulting in the large background at low angles. 
Table S 1. Crystallographic structure parameters from Rietveld refinements of $\mathrm{BaTiO}_{2.7} \mathrm{H}_{0.3}$ and $\mathrm{BaTiO}_{2.7} \mathrm{H}_{0.15} \mathrm{~F}_{0.15}$

\begin{tabular}{lllllllc}
\hline Compound & Atom & Site & $x$ & $y$ & $z$ & Occ. & $100 U_{\text {iso }}$ \\
\hline${ }^{1} \mathrm{BaTiO}_{2.7} \mathrm{H}_{0.3}$ & $\mathrm{Ba}$ & $1 b$ & 0.5 & 0.5 & 0.5 & 1 & $0.27(1)$ \\
$P m-3 m$ & $\mathrm{Ti}$ & $1 a$ & 0 & 0 & 0 & 1 & $0.76(2)$ \\
$a=4.02914(9) \AA$ & $\mathrm{O} / \mathrm{H}$ & $3 d$ & 0.5 & 0 & 0 & $0.904(6)$ & $1.48(9)$ \\
$\mathrm{R}_{w p}=6.73 \%, \mathrm{R}_{p}=4.94 \%$, & $\chi^{2}=1.49$ & & & & & \\
\end{tabular}

$\begin{array}{llllllll}\mathrm{BaTiO}_{2.7} \mathrm{H}_{0.15} \mathrm{~F}_{0.15} & \mathrm{Ba} & 1 b & 0.5 & 0.5 & 0.5 & 1 & 0.20(2) \\ P m-3 m & \mathrm{Ti} & 1 a & 0 & 0 & 0 & 1 & 0.40(2) \\ a=4.02608(9) \AA & \mathrm{O} / \mathrm{F} & 3 d & 0.5 & 0 & 0 & 0.954(6) & 1.41(8) \\ \mathrm{R}_{w p}=4.33 \%, \mathrm{R}_{p}=3.40 \%, \chi^{2}=1.69 & & & & & \end{array}$

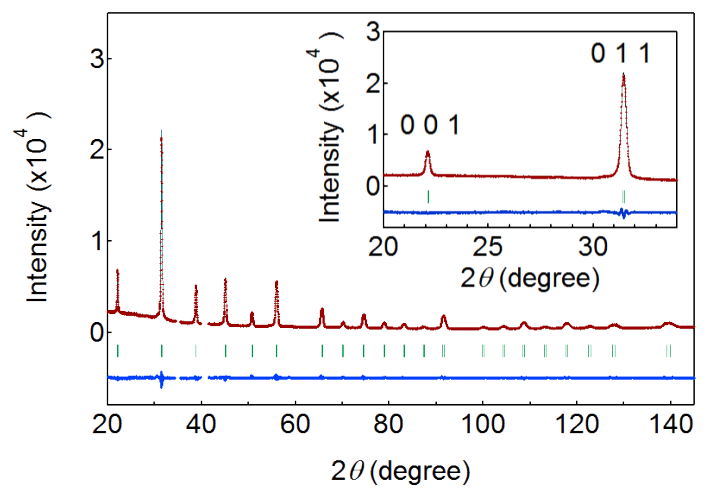

Figure S3. Rietveld refinement of $\mathrm{X}$-ray diffraction data of $\mathrm{BaTiO}_{2.7} \mathrm{H}_{0.15} \mathrm{~F}_{0.15}(\lambda=1.5418 \AA)$ 